\title{
Investigating the Role of Stakeholders in Agile Information Systems Development Projects: A Mixed Methods Approach
}

\author{
Veronika Huck-Fries \\ Technical University of Munich \\ veronika.huck-fries@tum.de
}

\author{
Francisca Nothaft \\ Technical University of Munich \\ francisca.nothaft@tum.de
}

\author{
Manuel Wiesche \\ TU Dortmund University \\ manuel.wiesche@tu-dortmund.de
}

\begin{abstract}
Agile information systems development (ISD) strives for a high amount of interaction between the agile team and stakeholders to ensure that high quality software within commonly defined project goals is produced. The literature has acknowledged that agile ISD significantly changes the work of team members. How do agile practices affect the work of stakeholders? Unfortunately, little theory exists to answer this question. This paper addresses this gap by investigating the effect of agile practices on stakeholders' job satisfaction. Adopting a mixedmethods approach, we use a review of the literature with an exploratory case study to develop the theoretical model, which was evaluated with a survey among stakeholders in agile ISD projects. We contribute to agile ISD literature by providing empirical evidence on stakeholders' job satisfaction and highlight the relevance of interaction and collaboration between team members and stakeholders in agile ISD projects.
\end{abstract}

\section{Introduction}

"Every line of code costs money." [1]. It is thus a commonly defined goal for organizations to develop software that meets stakeholder requirements and their actual needs. However, reality is different: $44 \%$ of features and functions are not used by stakeholders, ending up in higher costs on the company side [2].

Adherence to agile principles might be an approach to tackle this challenge. Agile information systems development (ISD) strives for short iterations and a high amount of interaction and continuous integration of stakeholders throughout the entire development process [3, 4], which contributes to a better understanding and satisfaction of stakeholders [5, 6]. Stakeholders such as customers, partners, investors, key employees or board members [7] make requirements on a product to be developed and are the ones who can best judge the success or failure of a product on the day of delivery [8]. Therefore, [9] and [10] stress that stakeholders play an important role in the software development process and that they can be seen as "a key factor in the success of any project".

While practice claims and research increasingly recognizes that agile ISD significantly changes the work of team members [11] and makes them more satisfied in their jobs [11, 12], the current literature neglects how agile ISD affects stakeholders. On the one hand, stakeholders are increasingly involved in the software development process when agile practices are applied, which might enable them to have more direct impact on the fit between requirements and functional software and thus increase their satisfaction at work. On the other hand, the high amount of interaction between stakeholders and agile team members in agile ISD might require higher technical skills and continuous usage of information and communication technologies, ending up in feelings of technostress [13] and decreased satisfaction at work.

The agile ISD literature is currently limited by explaining how agile ISD affects stakeholders. This research addresses the current shortcomings and examines the phenomenon of stakeholders' job satisfaction (SJS) in agile ISD projects. We aim to answer the research question: How do agile practices affect stakeholders' job satisfaction? To elucidate this research question, we draw on a metatheoretical framework of job satisfaction [14] and apply a mixed-methods approach [15]. Job satisfaction might result from the perception of meaningfulness at work as well as from the frequency of interaction. We theorize that these constructs are affected through the use of agile practices and provide empirical evidence that they mediate the relationship between agile practices and SJS. 
The remainder of this paper is as follows: in the theoretical background section, we outline the role of SJS in agile ISD projects and the job characteristics model (JCM). Afterwards, we explain the qualitative part of the study, develop the research model and hypotheses and present the method and the results. Finally, contributions for theory and practice as well as limitations and future research are discussed.

\section{Theory building and related work}

\subsection{Stakeholders in agile ISD}

In order to be successful, the development teams have to address the needs of various stakeholders [16]. Stakeholders are the ones who make the requirements on the product to be developed and can therefore best judge at the day of delivery whether they are satisfied with the results and whether their needs have been met or not $[8,16]$. Other stakeholders may not have specific product requirements, but they might have expectations of the company's profit [17]. Requirements describe what a system should do (or not do) according to stakeholders' needs in a certain situation [16]. Following approaches such as the waterfall model, all product requirements are defined with some stakeholders in a separate step at the beginning of the development and a finished product is presented at the end of the implementation [18]. In contrast, agile methodologies foster continuous stakeholder participation throughout the whole development process $[4,8,18]$ and each iteration is used to present an increment of the product to the stakeholders and to obtain feedback $[18,19]$. Thus, the advantage of an agile approach is to respond to any kind of change e.g. new stakeholder requirements, technologies or other varying environmental conditions [20].

\subsection{The job characteristics model}

As theoretical foundation for the entire research, the job characteristics model (JCM) by [14] has been chosen. This framework seems appropriate for the proposed work, as the model reflects how different job characteristics influence job satisfaction. "Job satisfaction" is defined as "the extent of positive emotional response to the job resulting from an employee's appraisal of the job as fulfilling or congruent with the individual's values" [21]. JCM states that core job characteristics affect job satisfaction. Job characteristics include skill variety, task identity, task significance, autonomy and feedback from the job.
A company is in constant exchange with various stakeholders [16]. While earlier studies examined stakeholders' satisfaction as an indicator for project success [8], is emphasized that in this research, job satisfaction is investigated from a stakeholders' view.

\subsection{Related work on stakeholders' job satisfaction}

In the examination of related work, four studies are identified who investigate SJS. [22] analyze the direct relationship between the quality of information systems and users' job satisfaction. In contrast, [23] extend the JCM to offer a user-centered view and found that users' job satisfaction also depends on technology characteristics of a system. [13] address technostress and the impact on users' job satisfaction as well as on their organizational commitment and their turnover intention. The most important results summarized: stress factors "decrease job satisfaction, leading to decreased organizational and continuance commitment", while factors that reduce stress show the opposite effect [13]. Lastly, [24] examine potential variables that affect the perceived job satisfaction of enterprise resource planning system users.

Despite this rather small number of research projects on the topic of SJS so far, the relevance is well known. For example, [23] emphasize that "understanding the causes of job satisfaction is a key to success for all firms". This strengthens the intention to carry out the study and in particular to address this issue. Furthermore, it is astonishing that no studies have examined SJS in an agile environment. As many authors name stakeholders as an important success factor of a project $[10,25]$, we therefore consider it valuable to investigate SJS in an agile context. Moreover, since research mainly focuses on the stakeholder groups "customer" or "user" - but this perspective should be extended [26], a holistic view of stakeholders appears reasonable. Conclusively, the analysis of job satisfaction from a stakeholders' perspective seems appropriate to contribute to more human-oriented research [27].

\subsection{The mixed-methods design}

A mixed-methods approach [28] is chosen as study design for this research, combining both qualitative and quantitative parts within a research project [28]. [28] stress that the advantage of this procedure is that it provides a much more comprehensive insight into a phenomenon. In this study, phase I is the qualitative element while phase 
II covers the quantitative part. We classified our study as a mixed-methods multistrand [15] and follow a sequential exploratory design [29], understanding constructs and proposing relationships within a qualitative approach and testing these assumptions through quantitative data analysis.

\subsection{Phase I: The qualitative study}

The qualitative interviews were drawn from an exploratory case study of GAMMA (a pseudonym), enabling us to gain specific insights and experiences from real context [30]. GAMMA is a globally operating enterprise in the automotive sector with approximately 135.000 employees worldwide. This includes employees within the headquarters as well as within the several national sales companies around the world. At the moment, they are facing the trend of the increasing introduction of agile working methods: in 2017, the company started to transform individual departments and areas. Beginning with the IT sector, other areas such as aftersales are still being transformed into agile working methods. However, this means that there is currently a very heterogeneous landscape within the company with regard to the introduction of new working approaches. In order to reflect this diversity, this research is conducted over the whole organization and not limited to one single department, enabling us to gain insights of the entire organization. GAMMA decided to work according to the LeSS approach. Since LeSS only provides a framework [31], divisions have made their own adaptations due to its situation.

We interviewed six relevant employees, including roles such as Scrum Master, Community Manager and Transformation Supervisor from a location in Germany. A distinction is made between internal (solid line) and external (dashed line) stakeholders (see figure 1). In this case, the term internal stakeholder is used when a group of people or an institution is part of the company. In contrast, all groups of people or institutions that are not part of the enterprise and thus have an external impact on it are referred to as external stakeholders.

Within the organization, employees who in some way make requirements on a product are regarded as internal stakeholders. Typical external stakeholders include users, customers and institutions like the government. The group of internal stakeholders in this company is generally further split into employees from a department who are responsible for a certain topic, people from the hierarchy or persons working for one of the worldwide subsidiaries. Despite this division, according to interview partner number 1
(IP1), those who finally pay money for the company are seen as the "real" stakeholders. Nevertheless, they all have in common that they make requirements on a product to be developed, regardless of which group they belong to (internal or external) (see figure 1).

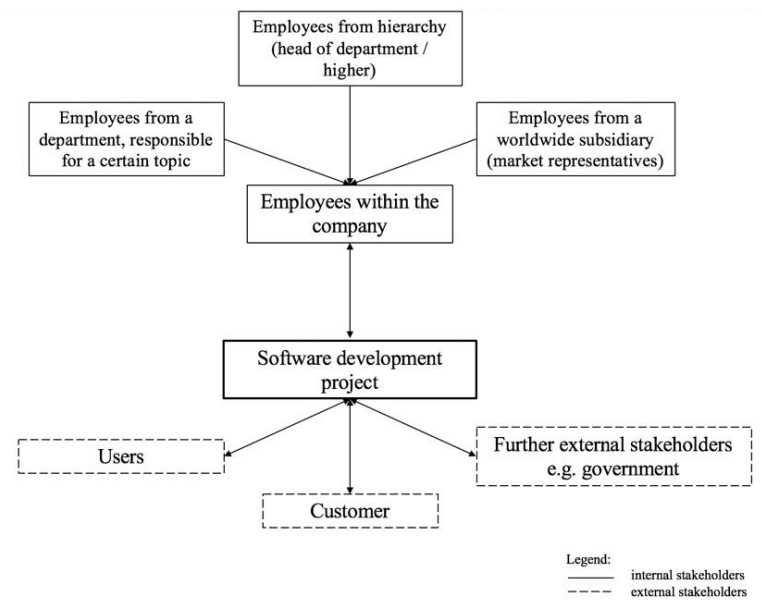

Figure 1. Stakeholder groups mentioned in the expert interviews

All interview partners confirm that satisfaction of stakeholders is very important. They see this as an opportunity to develop in a customer-centric manner, thereby creating added value and, for example, supporting people in their daily work with userfriendly software. IP4 formulates the following aspect: "Certainly, during the transition phase the dissatisfaction can increase because the transition can also be a bit chaotic. And it leads to confusion because things change and you can't always say right away how that changes. That's certainly an aspect. In the final stage, when we really arrived in the agile world, I would hope that stakeholders would feel better off than in the past."

Furthermore, all interviewees state that the most noticeable change is the increasing integration of stakeholders into the software development process. This leads to more interaction between the development team and the relevant stakeholders (e.g. joint meetings) and, as a result, to a perceived higher time expenditure on both sides. The fact that stakeholders are more involved in an agile environment is viewed both positively and negatively by the various experts. For example: IP5 declares that it is an opportunity to have a greater say, whereas IP 3 states that some internal stakeholders wonder why they have to introduce requirements more than once.

In contrast, a phenomenon that most interviewees have described as a positive influencing factor is here referred to as perceived meaningfulness of one's own work. The quotation from IP1 emphasizes this: "I am convinced that people work happier and even more efficiently when they feel that they have made a 
contribution. It's not the same when I buy something or when I do something myself. When I do it myself, it is much more valuable to me and brings me more joy."

Table 1 provides sample quotes pertaining theoretical constructs evolving from the interviews. These findings and fundamentals of the JCM lead us to the relevant constructs as predictors of SJS: perceived meaningfulness and interaction frequency.

Table 1. Variables that emerged from the interviews and sample supporting quotes

\begin{tabular}{|l|l|}
\hline $\begin{array}{l}\text { Variable } \\
\text { suggested } \\
\text { merceived } \\
\text { fulness }\end{array}$ & $\begin{array}{l}\text { Sample quote } \\
\text { "Everyone involved realizes that they are } \\
\text { producing something and that what they are } \\
\text { doing is meaningful. The employees do } \\
\text { something meaningful. They move things } \\
\text { forward and create an effect with what they } \\
\text { do. And they understand it's a valuable } \\
\text { activity." (IP6) } \\
\text { "I involve everyone when requirements are to } \\
\text { be introduced and implemented, because I } \\
\text { often don't have the knowledge to do that. } \\
\text { This works well because they are experts } \\
\text { concerning their tools and their data. And } \\
\text { there the engagement is actually also great, } \\
\text { because they know that the service systems } \\
\text { that we now have outside at the dealer run } \\
\text { very well and are accepted." (IP5) }\end{array}$ \\
\hline $\begin{array}{l}\text { Inter- } \\
\text { action } \\
\text { frequency }\end{array}$ & $\begin{array}{l}\text { "Now that we all want closer contact with } \\
\text { stakeholders and we are also forced by the } \\
\text { in order to better understand them. In order to } \\
\text { get close to them, to show first results, i.e. } \\
\text { simply the time expenditure for them is high. } \\
\text { Hopefully in the long run it will get down } \\
\text { again, because they will get better and more } \\
\text { suitable solutions. I think it'll pay off for them } \\
\text { later. But it may be that at the moment they } \\
\text { feel that they have to do more than in the } \\
\text { past." (IP4) }\end{array}$ \\
\hline
\end{tabular}

\section{Research model and hypotheses development}

JCM acts as a metatheoretical framework of the study and supported the identification of specific constructs affecting SJS.

It is assumed that agile practices have a positive impact on stakeholders' perceived meaningfulness. Working according to an agile approach means involving stakeholders throughout the entire process [4]. This allows them to give feedback on current developments and at the same time to see what is happening with their requirements [27, 32]. Furthermore, to quote IP3 from the expert interviews: "in the end, he [the stakeholder] can say that this small part within the system landscape which is available worldwide, came from him and somehow helps all his colleagues". All of this should lead to an increase in the perceived meaningfulness of the stakeholders' work due to agile ISD. [11] applied the JCM to agile ISD and found a positive and significant effect of agile software development approaches on task significance. As task significance is defined as "the degree to which the job has a substantial impact on the lives or work of other people" [33], it seems comparable with perceived meaningfulness. Furthermore, it is supposed that perceived meaningfulness has a positive influence on SJS. On the one hand, this is derived from the results of the expert interviews, which identified perceived meaningfulness as a potential influencing factor. On the other hand, this statement is supported by the literature. [34] found evidence of a positive relationship between task significance and job satisfaction. Furthermore, [35] observed "a positive relationship between the nature of the task and engagement", whereas [36] verified a positive relationship between meaningfulness and work engagement. We thus postulate that

H1. Perceived meaningfulness mediates the positive effect of agile practices on SJS, that is, there is a positive, indirect effect of agile practices via perceived meaningfulness on SJS.

One of the main changes that occur in agile ISD is that the interaction between stakeholders and development teams increases [3, 8]. Regular joint meetings should enable the continuous exchange and strengthen the integration of stakeholders over the entire development process $[37,38]$. We thus argue:

H2. Interaction frequency mediates the positive effect of agile practices on SJS, that is, there is a positive, indirect effect of agile practices via interaction frequency on SJS.

\section{Phase II: The survey}

\subsection{Participants and data collection procedure}

Data were collected via an online-survey in August and September 2019 among stakeholders in agile ISD projects within the case study company. The such-called snowball sample is applied to distribute the survey [see e.g. 39]. This means a certain number of people are contacted and at the same time asked to send the survey to other potential participants [39]. This approach is chosen in order to reach as many people as possible in an unknown population. Furthermore, an a priori calculation of the 
minimum sample size was done to "attain the desired power for the specified $\alpha$ [significance criterion] and hypothesized ES [effect size]" [40]. Thereby, "the statistical power of a significance test is the longterm probability" to reject the basic hypothesis. For calculating the required minimum sample size for a statistical power of .80, [40] is used. Moreover, the minimum sample size is evaluated by means of the $\mathrm{G}^{*}$ Power (version 3.1) program. According to the recommendations of [40], at least 76 people should participate in the survey to achieve a statistical power of .80 under the conditions that $\alpha=.05$ (significance criterion) and $\mathrm{f} 2=.15$ (medium effect size). This value matches the calculation of $\mathrm{G}^{*}$ Power which recommends a sample size of $\mathrm{n}=77$ (settings: $\mathrm{F}$ tests; linear multiple regression: fixed model, R2 deviation from zero; a priori; $\mathrm{f} 2=.15 ; \alpha=.05$; power $=.80$; number of predictors $=3$ ).

An email with participation information and the link to the survey is sent to both mailing lists and individuals. In addition to stakeholders who have already been identified, persons who are to act exclusively as intermediaries are also included. The authors contacted about 500 people and 112 participants took part in the survey (response rate: $22,4 \%$ ). Only participants who have answered more than $85 \%$ of the survey are included in the analysis [41]. In addition, the first question is designed as a screening question "to ensure that only individuals who meet the prescribed criteria" are considered [41]. As a result, the sample size is reduced to a final sample of 50 participants. By comparing early and late respondents (the first and the last 20) based on their demographic data, we accounted for nonresponse bias [42]. The results of the analysis suggest that non-response bias was not likely to affect the results $(p>0.5)$. Main participants $(64 \%)$ were employees who see themselves as experts for a certain topic and who, from this role, set requirements for a specific service. Further 8\% replied to be at least head of department or higher and $14 \%$ of the participants work in one of the national sales companies. Another $14 \%$ used the option "others" and indicated to what extent they make requirements on a service. Furthermore, the participants replied that they spend on average $42.18 \%(\mathrm{SD}=32.50)$ of their weekly time on tasks in their role as a stakeholder. This indicates that they have other responsibilities besides their stakeholder activities. In addition to the questions about their role, the professional experiences were also surveyed. $84 \%$ of the participants had between 11 and 20 years of overall work experience; no one had more than 20 years and only $2 \%$ less than 3 years. While $36 \%$ said they had been working for the case study company for at least 16 years, $20 \%$ stated they had worked there for less than 3 years (see table 2).

Table 2. Demographics of participants $(\mathrm{N}=50)$

\begin{tabular}{|l|c|}
\hline Stakeholders' role & Percentage \\
\hline Expert for a certain topic & $64 \%$ \\
\hline Head of a department or higher & $8 \%$ \\
\hline Expert from a national sales company & $14 \%$ \\
\hline Others & $14 \%$ \\
\hline Working experience & \\
\hline$<3$ years of work experience & $2 \%$ \\
\hline $3-5$ years of work experience & $6 \%$ \\
\hline $6-10$ years of work experience & $8 \%$ \\
\hline $11-15$ years of work experience & $26 \%$ \\
\hline $16-20$ years of work experience & $58 \%$ \\
\hline$>20$ years of work experience & $0 \%$ \\
\hline $\begin{array}{l}\text { Working experience with current } \\
\text { employer }\end{array}$ & \\
\hline$<3$ years of work experience & $20 \%$ \\
\hline $3-5$ years of work experience & $8 \%$ \\
\hline $6-10$ years of work experience & $20 \%$ \\
\hline $11-15$ years of work experience & $36 \%$ \\
\hline $16-20$ years of work experience & $0 \%$ \\
\hline$>20$ years of work experience & \\
\hline
\end{tabular}

\subsection{Measures}

In order to measure the agile practices "burndown charts (BD)" and "iterative delivery (ID)", the questions of [34] are used. The three items for the variable "review (RV)" are an own creation which is oriented at the research of [34]. Since the other methods summarized by [11] under the term "software-development approach practices" have no influence on or connection to stakeholders, they are not considered in this research. Furthermore, the two project management practices (daily stand-up meeting and retrospectives) refer only to the team and are therefore not relevant to stakeholders either. Only the "review" is added as a central event for exchange between the team and stakeholders (see [37]), as this is not considered in the work of [11].

Perceived meaningfulness (PM) is used from [43]. Interaction frequency (IF) is used from [44]. Stakeholders' job satisfaction (SJS) is measured on a three-item scale of [21]. A seven-point Likert scale ranging from "strongly disagree (1)" to "strongly agree (7)" with the answer "don't know" is used for all constructs except PM, where we excluded the answer option "don't know". All items have to be adapted to the target group, since the surveys 
conducted so far had focused more on the development team [e.g. 34] rather than on stakeholders. Stakeholders' role was a single item measure used as a control variable in the model.

\section{Results}

\subsection{Validity and reliability}

In order to examine the quality of measurement, reliability, convergent validity and discriminant validity of the various constructs are evaluated [41]. To assess the internal consistency reliability of constructs' indicators, Cronbach's alpha and composite reliability are typically calculated [41]. The convergent validity is being measured through the consideration of "the outer loadings of the indicators and the average variance extracted (AVE)" [41]. All items meet the criterion of convergent validity except SJS2 and PM3, which were accordingly excluded from the constructs. In addition, examining the average variance extracted leads to the assumption that convergent validity has been fulfilled by all constructs, as all values are above the mandatory 0.5 [41] (see Appendix). In order to measure the discriminant validity of the constructs used, several tests are considered: the cross-loadings of each indicator, the Fornell-Larcker criterion and the heterotrait-monotrait ratio (HTMT) [41]. Based on the results, the criterion "discriminant validity" is considered to be fulfilled.

Common method bias (CMB) refers to a problem in a research project when more variance is explained by the measurement method itself and is not due to the constructs [45]. In order to prevent CMB, participants were informed that the survey is carried out anonymously and thus answers are not traceable to individual persons. In addition, it is emphasized that participation is absolutely voluntary. Another source of $\mathrm{CMB}$ is item ambiguity and item complexity. In order to assess the extent of CMB, Harman's single-factor test is performed [45]. The analysis carried out contradicts this statement, therefore CMB is not found in this study.

\subsection{Analysis}

Before evaluating the model hypotheses, the significance of the control variable was investigated. No significant effect of stakeholders' role was observed $(\mathrm{p}>0.05)$. We thus proceeded with the test of our mediation hypotheses using conditional process analysis [46]. Conditional process analysis uses fundamentals of least square regression and bootstrapping to estimate moderating and mediating effects. Bootstrapping procedures have been found to outperform Sobel test and the three steps approach proposed by [46]. All hypotheses were tested using the PROCESS macro (version 3) [47] in SPSS 24.0. For testing hypothesis 1 and 2, we employed PROCESS model 6 with two mediators with a $95 \%$ confidence interval and 1000 bootstrap resamples. First, a positive indirect effect of agile practices on SJS via perceived meaningfulness was found $(b=$ $0.004, \mathrm{SE}=0.062, \mathrm{LL}=-0.111, \mathrm{UL}=0.138)$, partially supporting H1. Second, a significant positive indirect effect of agile practices on SJS via interaction frequency was found $(b=0.304, \mathrm{SE}=0.137$, $\mathrm{LL}=0.022$, $\mathrm{UL}=0.565$ ), supporting $\mathrm{H} 2$ (see figure 2).

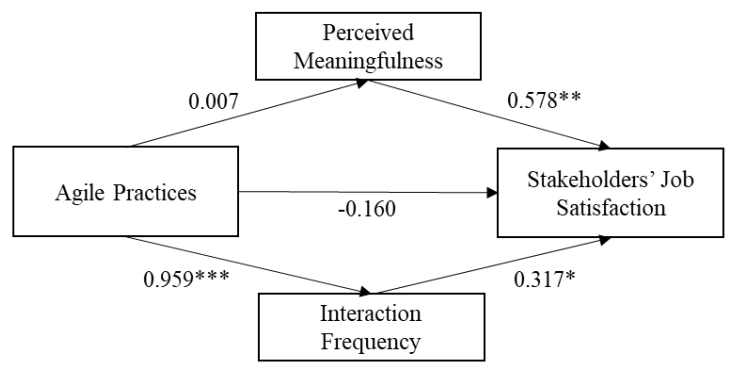

Figure 2. The research model with results $* p<0.05 ; * * p<0.01 . ; * * * p<0.001$

\section{Discussion and contributions}

In this research, we set out to examine the effect of agile practices on SJS. We accomplished this goal by conceptualizing and empirically evaluating a model proposing that agile practices increase SJS via perceived meaningfulness and interaction frequency. Results from interviews and survey data among stakeholders of agile ISD projects mainly support our model. This research contains several implications for theory to the agile ISD and job satisfaction literature, which are described in the following.

\subsection{Theoretical contributions}

This study's contribution to theory lies in extending the dominant perspective of how agile practices affect team members [11, 48] in the agile ISD literature by building on recent research acknowledging the importance of stakeholders in agile ISD projects $[9,10]$. We do so by examining how agile practices affect SJS and provide empirical evidence that this relationship is mediated by perceived meaningfulness and interaction frequency. In particular, the results indicate a partial mediation significant relationship between agile practices and perceived meaningfulness and a significant effect of 
perceived meaningfulness on SJS, indicating a partial mediation effect. Interaction frequency fully mediates the relationship between agile practices and SJS. This finding implies that, besides software developers and team members of agile ISD projects, stakeholders' work significantly changes through the use of agile practices. This finding also implies that future studies on agile ISD might be enlarged by the perspective of stakeholders.

While several constructs of the existing literature on agile ISD can be used, there is a need to develop new constructs to account for advances in agile project management, such as review meetings. This research makes a first step towards this end by conceptualizing and validating a construct for review meetings. The psychometric criteria of the new construct meet the existing standards and provide the possibility to use it for future studies. We furthermore enlarge the existing body of knowledge on agile ISD by using well-established constructs from the organizational psychology literature to the context of agile ISD.

While agile ISD can support organizations to produce software that meets stakeholders' requirements and fits their actual needs, and team members are more satisfied in agile ISD projects [11], this research is a first step to examine how stakeholders are affected through the use of agile practices. This is important for two reasons. First, the literature on agile ISD has highlighted the role of stakeholders, but has given them little attention so far. Second, failure of ISD projects, such as meeting time, budget and quality requirements, has traditionally been a key concern in the ISD literature $[49,50]$. Stakeholders are the ones who can best judge the success or failure of a product on the day of delivery [8] and can therefore be seen as an important factors for successfully completing ISD projects [9, 10].

Based on the results of our qualitative interviews, we had hypothesized that agile practices will lead to perceptions of higher meaningfulness of work among stakeholders, which increases their job satisfaction. The results of the quantitative study did, however, only partially confirm this assumption. While we found a significant effect of perceived meaningfulness on SJS, agile practices do not significantly affect meaningfulness at work among stakeholders. These findings are consistent with traditional theories of job satisfaction such as JCM. [14] propose that task significant and meaningfulness at work are positively related to job satisfaction. Broadening this perspective to the context of agile ISD projects, [11] argue that agile ISD provides a form of a natural work unit. Contrasting to work fractionalization, where employees are only able to finish a part of the work with the overall goal to deliver a task, agile ISD forms natural work units through the possibility to select a task to complete the feature, which provides employees perceptions of ownership towards their job and increases their perceived meaningfulness as well as task identity and task significance [11, 14]. Although agile ISD promotes continuous integration of stakeholders throughout the entire development process [3, 4], we did not find a direct influence on stakeholders' perceived meaningfulness at work.

Prior research on agile ISD has pointed out the importance of interaction among the agile team and stakeholders [3, 8, 51], but has left consequences of this for future research. This paper contributes to the literature stream by providing empirical evidence that continuous interaction among the agile team and stakeholders fully mediates the relationship between agile practices and SJS. As a result, we show that SJS can be influenced through the amount of interaction. Facing the increasing amount of virtual and dispersed ISD teams and stakeholders, these findings might be particularly important for collaborating across boundaries.

\subsection{Practical contribution}

Stakeholders are crucial for running ISD projects. Organizations spend a lot of effort to fulfill their requirements and avoid costs caused by dysfunctional features and functions. Hence, the investigation of how agile practices affect SJS, which might contribute to a reduction of costs, is important for practitioners. The results of this study implicate that organizations might use agile practices in order to support SJS at work. Particularly, the amount of interaction incorporates SJS. In addition, organizations are encouraged to understand the important role of SJS and adjust ISD projects accordingly.

\subsection{Limitations and future work}

This study's findings are limited in several ways. First, as it is common in IS research [e.g. 48, 52], we focused on a single company when conducting this study. On the one hand, it allows us to control for differences between companies; on the other hand, the results might differ compared to other organizations and branches. Research indicates that organizational characteristics, such as organizational skills, affect the use of agile ISD practices [48]. We thus encourage future research to use a broader 
sample to investigate the phenomenon of stakeholders in agile ISD projects in order to increase the generalizability of results. Second, characteristics of implementing agile practices in organizations are very heterogenous; for example, agile practices can be introduced in waves or at one timepoint. While data for this study have been collected at one timepoint, future studies might use a longitudinal study design to account for differences in stability of the environment.

\subsection{Conclusion}

Facing an increasing number of ISD projects who are conducted using agile practices, it is needed for IS researchers to offer practitioners deeper knowledge and insights on how agile practices affect key predictors of ISD project success, such as stakeholders. Although prior research has examined how agile practices affect job satisfaction among team members of the ISD team, is was not examined how stakeholders are influenced through the use of agile practices. Using the JCM as a theoretical base, this study found that perceived meaningfulness and interaction frequency mediate the relationship between agile practices and SJS. Project leaders of agile ISD projects can use these findings by appropriately selecting and applying agile practices in their projects. Given that stakeholders are considered as a key outcome variable for ISD project success [10], the extension of earlier findings on job satisfaction to stakeholders is particularly important.

\section{References}

[1] C. Hibbs, S. Jewett, and M. Sullivan. 2009. The art of Lean Software Development: A Practical and Incremental Approach. 2009, Sebastopol: O'Reilly Media, Inc.

[2] The Standish Group. CHAOS REPORT 2015. 2015 03.08.2020]; Available from: https://www.standishgroup.com/sample_research_files/CH AOSReport2015-Final.pdf.

[3] S. Kudaravalli, S. Faraj, and S.L. Johnson, 2017. A Configural Approach to Coordinating Expertise in Software Development Teams. MIS Quarterly, 41(1) (2017), p. $43-$ 64.

[4] T. Dingsøyr, et al., 2012. A decade of agile methodologies: Towards explaining agile software development. The Journal of Systems and Software, 85 (2012), p. 1213-1221.

[5] T. Dybå and T. Dingsøyr, 2008. Empirical studies of agile software development: A systematic review. Information and Software Technology, 50 (2008), p. 833859. DOI: 10.1016/j.infsof.2008.01.006.

[6] S.L. Pan and G. Pan, 2006. Customer-centric IS application development: lessons from a case of developing an online auction site. Communications of the Association for Information Systems, 18(18) (2006), p. 395-412. DOI: 10.17705/1CAIS.01818.

[7] R. Banfield, M. Eriksson, and N. Walkingshaw. 2017. Product leadership: How top product managers launch awesome products and build successful teams. 2017, Sebastopol: O'Reilly Media, Inc.

[8] P. Serrador and J.K. Pinto, 2015. Does Agile work?-A quantitative analysis of agile project success. International Journal of Project Management, 33(5) (2015), p. 10401051.

[9] E.-M. Schön, J. Thomaschewski, and M.J. Escalona, 2017. Agile Requirements Engineering: A systematic literature review. Computer Standards \& Interfaces, 49 (2017), p. 79-91. DOI: 10.1016/j.csi.2016.08.011

[10] Y. Ben-Chaim, et al., 2010. Engaging stakeholders in globally distributed software development processes. in MCIS 2010 Proceedings, 14.

[11] J. Tripp, C. Riemenschneider, and J. Thatcher, 2016. Job Satisfaction in Agile Development Teams: Agile Development as Work Redesign. Journal of the Association for Information Systems, 17(4) (2016), p. 267. DOI: $10.17705 / 1$ jais.00426.

[12] J. Highsmith. 2002. Agile Software Development Ecosystems. 2002, Boston: Addison Wesley.

[13] T. Ragu-Nathan, et al., 2008. The consequences of technostress for end users in organizations: Conceptual development and empirical validation. Information systems research, 19(4) (2008), p. 417-433.

[14] J.R. Hackman and G.R. Oldham, Work redesign, E. Schein and R. Bekhard, Editors. 1980, Addison Wesley: New York.

[15] V. Venkatesh, S.A. Brown, and H. Bala, 2013. Bridging the qualitative-quantitative divide: Guidelines for conducting mixed methods research in information systems. MIS Quarterly: Management Information Systems, 37(1) (2013), p. 21-54.

[16] D. Leffingwell. 2011. Agile Software Requirements: Lean Requirements Practices for Teams, Programs, and the Enterprise. 2011: Addison-Wesley.

[17] S.G. Scott and V.R. Lane, 2000. A stakeholder approach to organizational identity. Academy of Management review, 25(1) (2000), p. 43-62.

[18] A.S. Koch. 2005. Agile Software Development. Evaluating the Methods for Your Organization. 2005, Norwood: Artech House, Inc.

[19] L. Cao, et al., 2009. A framework for adapting agile development methodologies. European Journal of Information Systems, 18(4) (2009), p. 332-343. DOI: 10.1057/ejis.2009.26.

[20] K. Beck, 1999. Embracing Change with Extreme Programming. IEEE Computer, 32(10) (1999), p. 70-78.

[21] M.G. Morris and V. Venkatesh, 2010. Job characteristics and job satisfaction: understanding the role of enterprise resource planning system implementation. MIS Quarterly, 34(1) (2010), p. 143-161.

[22] K. Joshi and A. Rai, 2000. Impact of the quality of information products on information system users' job satisfaction: an empirical investigation. Information Systems Journal, 10(4) (2000), p. 323-345. 
[23] K. Liere-Netheler, et al., 2017. Towards the User: Extending the Job Characteristics Model to Measure Job Satisfaction for ERP Based Workplaces-A Qualitative Approach. in CONF-IRM 2017 Proceedings, 37.

[24] S.F. Wamba and M. Bhattacharya, Determinants of Perceived Job Satisfaction From ERP-enabled Emergency Service Adoption: An Empirical Study, in Twenty-first Americas Conference on Information Systems. 2015: Puerto Rico.

[25] B. Boehm and R. Turner. 2003. Balancing agility and discipline: A guide for the perplexed. 2003, Boston: Addison-Wesley Professional.

[26] K. Conboy and L. Morgan, 2011. Beyond the customer: Opening the agile systems development process. Information and Software Technology, 53(5) (2011), p. 535-542.

[27] A. Cockburn and J. Highsmith, 2001. Agile software development: The people factor. Computer, 43(11) (2001), p. 131-133.

[28] V. Venkatesh, S.A. Brown, and H. Bala, 2013. Bridging the qualitative-quantitative divide: Guidelines for conducting mixed methods research in information systems. MIS Quarterly, 37(1) (2013), p. 21-54.

[29] J.W. Creswell, V.L. Plano Clark, and A.L. Garrett, 2008. Methodological issues in conducting mixed methods research designs. Advances in mixed methods research, (2008), p. 66-83.

[30] A. Bogner, B. Littig, and W. Menz. 2014. Interviews mit Experten: eine praxisorientierte Einführung. 2014, Wiesbaden: Springer-Verlag.

[31] C. Larman and B. Vodde. 2016. Large-Scale Scrum. More with LeSS. 2016, Boston: Addison Wesley.

[32] L. Williams and A. Cockburn, 2003. Agile software development: it's about feedback and change. IEEE Computer, 36(6) (2003), p. 39-43.

[33] J.R. Hackman and G.R. Oldham, 1976. Motivation through the design of work: Test of a theory. Organizational behavior and human performance, 16(2) (1976), p. 250-279.

[34] J.F. Tripp, C. Riemenschneider, and J.B. Thatcher, 2016. Job satisfaction in agile development teams: Agile development as work redesign. Journal of the Association for Information Systems, 17(4) (2016), p. 267-307.

[35] F. Candatten, et al., 2013. Engagement of Information Technology Professionals with Their Work. in Americas Conference on Information Systems. Illinois, Chicago.

[36] M. Geldenhuys, K. Laba, and C.M. Venter, 2014. Meaningful work, work engagement and organisational commitment. SA Journal of Industrial Psychology, 40(1) (2014), p. 01-10.

[37] K. Schwaber and J. Sutherland. The Scrum Guide. The Definitive Guide to Scrum: The Rules of the Game. 2017 [15.08.2020]; Available from: https://www.scrum.org/resources/scrum-guide.

[38] C. Mann and F. Maurer, 2005. A case study on the impact of scrum on overtime and customer satisfaction. in Agile Development Conference (ADC'05). IEEE, 70-79.

[39] G.R. Sadler, et al., 2010. Recruitment of hard-to-reach population subgroups via adaptations of the snowball sampling strategy. Nursing \& Health sciences, 12(3) (2010), p. 369-374.
[40] J. Cohen, 1992. A power primer. Psychological bulletin, 112(1) (1992), p. 155-159.

[41] J.F. Hair Jr., et al. 2017. A Primer on Partial Least Squares Structural Equation Modeling (PLS-SEM). 2 ed. 2017: SAGE Publications.

[42] J.S. Armstrong and T.S. Overton, 1977. Estimating nonresponse bias in mail surveys. Journal of marketing research, 14(3) (1977), p. 396-402.

[43] J.R. Hackman and G.R. Oldham. 1980. Work redesign. 1980: Addison-Wesley.

[44] N.R. Anderson and M.A. West, 1998. Measuring climate for work group innovation: development and validation of the team climate inventory. Journal of Organizational Behavior, 19(3) (1998), p. 235-258.

[45] P.M. Podsakoff, et al., 2003. Common method biases in behavioral research: A critical review of the literature and recommended remedies. Journal of applied psychology, 88(5) (2003), p. 879-903.

[46] A. Hayes. 2013. Introduction to Mediation, Moderation, and Conditional Process Analysis: A Regression-Based Approach. 2013, New York: The Guilford Press

[47] A. Hayes. 2019; Available from: http://processmacro.org/index.html.

[48] V. Venkatesh, et al., 2020. How agile software development methods reduce work exhaustion: Insights on role perceptions and organizational skills. Information Systems Journal, n/a(n/a) (2020). DOI: 10.1111/isj.12282. [49] V. Balijepally, et al., 2009. Are two heads better than one for software development? The productivity paradox of pair programming. MIS Quarterly: Management Information Systems, 33(1) (2009), p. 91-118. DOI: $10.2307 / 20650280$.

[50] G. Lee and W. Xia, 2010. Toward agile: an integrated analysis of quantitative and qualitative field data on software development agility. MIS Quarterly: Management Information Systems, 34(1) (2010), p. 87114. DOI: $10.2307 / 20721416$.

[51] G. Melnik and F. Maurer, Comparative analysis of job satisfaction in agile and non-agile software development teams, in Extreme Programming and Agile Processes in Software Engineering. XP 2006., P. Abrahamsson, M. Marchesi, and G. Succi, Editors. 2006, Springer: Berlin Heidelberg. p. 32-42.

[52] L.M. Maruping, V. Venkatesh, and R. Agarwal, 2009. A control theory perspective on agile methodology use and changing user requirements. Information Systems Research, 20(3) (2009), p. 377-399.

\section{Appendix}

Table 3. Questionnaire and measurement items

\begin{tabular}{|c|l|l|}
\hline CS & \multicolumn{1}{c|}{ Items } \\
\hline & Original version & \multicolumn{1}{c|}{ Adapted version } \\
\hline \multirow{2}{*}{} & $\begin{array}{l}\text { Our team utilizes } \\
\text { visual indicators } \\
\text { (charts, graphs, etc.) } \\
\text { of how well we are } \\
\text { progressing } \\
\text { DURING a work }\end{array}$ & $\begin{array}{l}\text { DURING a work cycle, the } \\
\text { development team presents } \\
\text { to me as a stakeholder the } \\
\text { progress of the development } \\
\text { by using visual indicators } \\
\text { (charts, graphs, etc.) }\end{array}$ \\
\hline
\end{tabular}




\begin{tabular}{|c|c|c|}
\hline & cycle. & \\
\hline & $\begin{array}{l}\text { We use visual tools } \\
\text { that allow team } \\
\text { members to easily } \\
\text { tell if the work is } \\
\text { being completed on } \\
\text { schedule. }\end{array}$ & $\begin{array}{l}\text { Visual tools that are used by } \\
\text { the development team allow } \\
\text { me as a stakeholder to easily } \\
\text { tell if the work is being } \\
\text { completed on schedule. }\end{array}$ \\
\hline & $\begin{array}{l}\text { We plot our work } \\
\text { completed against } \\
\text { work planned on a } \\
\text { chart. }\end{array}$ & $\begin{array}{l}\text { The development team } \\
\text { presents the comparison of } \\
\text { completed work against } \\
\text { work planned to me as a } \\
\text { stakeholder by using a chart. }\end{array}$ \\
\hline \multirow{3}{*}{ 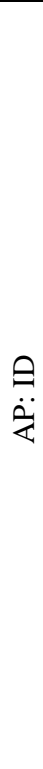 } & $\begin{array}{l}\text { At the beginning of } \\
\text { each work cycle, the } \\
\text { team and business } \\
\text { owners agree on } \\
\text { what will be } \\
\text { delivered during the } \\
\text { work cycle. }\end{array}$ & $\begin{array}{l}\text { At the beginning of each } \\
\text { work cycle, the development } \\
\text { team, business owners and } \\
\text { me as a stakeholder agree on } \\
\text { what will be delivered } \\
\text { during the work cycle. }\end{array}$ \\
\hline & $\begin{array}{l}\text { The team estimates } \\
\text { the amount of work } \\
\text { each feature will } \\
\text { require to be } \\
\text { completed. }\end{array}$ & $\begin{array}{l}\text { The development team gives } \\
\text { input as to how much work } \\
\text { can be completed in a work } \\
\text { cycle. }\end{array}$ \\
\hline & $\begin{array}{l}\text { Our team lets } \\
\text { business people } \\
\text { make business } \\
\text { decisions about } \\
\text { releases, and } \\
\text { technical people } \\
\text { make technical } \\
\text { decisions about } \\
\text { releases. }\end{array}$ & $\begin{array}{l}\text { As a stakeholder I can } \\
\text { introduce requirements } \\
\text { about releases, business } \\
\text { people can make business } \\
\text { decisions about releases, and } \\
\text { the technical people can } \\
\text { make technical decisions } \\
\text { about releases. }\end{array}$ \\
\hline \multirow{3}{*}{$\begin{array}{l}\vec{\alpha} \\
\dot{\alpha} \\
\dot{\alpha}\end{array}$} & (own) & $\begin{array}{l}\text { As a stakeholder, I am aware } \\
\text { that there is a review after } \\
\text { every work cycle. (definition } \\
\text { of review: at the end of each } \\
\text { work cycle, there is a } \\
\text { meeting to inspect the work } \\
\text { of the development team) }\end{array}$ \\
\hline & (own) & $\begin{array}{l}\text { In my role as a stakeholder I } \\
\text { am part of the review and } \\
\text { the results from the past } \\
\text { work cycle are presented to } \\
\text { me by the development } \\
\text { team. }\end{array}$ \\
\hline & (own) & $\begin{array}{l}\text { In my role as a stakeholder I } \\
\text { am able to give feedback to } \\
\text { the development team on the } \\
\text { results presented during the } \\
\text { review. }\end{array}$ \\
\hline$\sum_{\Omega}$ & $\begin{array}{l}\text { In general, how } \\
\text { significant or } \\
\text { important is your } \\
\text { job? That is, are the } \\
\text { results of your work } \\
\text { likely to } \\
\text { significantly affect } \\
\text { the lives or well- }\end{array}$ & $\begin{array}{l}\text { In your role as a stakeholder: } \\
\text { are the results of your work } \\
\text { likely to significantly affect } \\
\text { the lives of well-being of } \\
\text { other people? }\end{array}$ \\
\hline
\end{tabular}

\begin{tabular}{|l|l|l|}
\hline \multirow{1}{*}{$\begin{array}{l}\text { being of other } \\
\text { people? }\end{array}$} & $\begin{array}{l}\text { This job is one } \\
\text { where a lot of other } \\
\text { people can be } \\
\text { affected by how } \\
\text { well the work gets } \\
\text { done. }\end{array}$ & $\begin{array}{l}\text { In your role as a stakeholder, } \\
\text { the work you do in this role } \\
\text { is one where a lot of other } \\
\text { people can be affected by } \\
\text { how well this work gets } \\
\text { done. }\end{array}$ \\
\cline { 2 - 3 } & $\begin{array}{l}\text { The job itself is not } \\
\text { very significant or } \\
\text { important in the } \\
\text { broader scheme of } \\
\text { things. }\end{array}$ & $\begin{array}{l}\text { (In your role as a } \\
\text { stakeholder, the work you do } \\
\text { as a stakeholder itself is } \\
\text { NOT very significant or }\end{array}$ \\
\hline \multirow{4}{*}{$\begin{array}{l}\text { important in the broader } \\
\text { scheme of things.) }\end{array}$}
\end{tabular}

Table 4. Quality criteria of construct measures

\begin{tabular}{|c|c|c|c|c|c|}
\hline Construct & $\begin{array}{c}\text { \# of } \\
\text { Items }\end{array}$ & AVE & Alpha & $\mathbf{M}$ & SD \\
\hline AP: BD & 3 & 0.782 & .860 & 4.20 & 1.75 \\
\hline AP: ID & 3 & 0.773 & .852 & 5.23 & 1.41 \\
\hline AP: RV & 3 & 0.731 & .810 & 5.45 & 1.53 \\
\hline PM & $3(2)$ & 0.716 & .611 & 5.09 & 1.08 \\
\hline IF & 4 & 0.765 & .935 & 5.05 & 1.66 \\
\hline SJS & $3(2)$ & 0.779 & .719 & 5.01 & 1.19 \\
\hline
\end{tabular}

